\title{
Google Forms as a useful tool for online formative assessment of a pharmacotherapy course in Indonesia
}

\author{
L. Lailaturrahmi*, D. Permatasari, E. Badriyya, F.S. Wahyuni \\ Andalas University, Indonesia
}

Keywords

Formative Assessment

Google Forms

Online Quiz

Indonesia

*Corresponding author:

lailaturrahmi@phar.unand.ac.id
Summary: This case study aims to explore the utilisation of Google Forms as a tool for online formative assessment for the Pharmacotherapy of Infectious Diseases, Immune System, and Cancer (FAF 323) courses at Andalas University, Indonesia. The online formative assessment was conducted to assess students' progress after completing four online modules (Systemic Lupus Erythematosus, Drug Hypersensitivity Reaction, Tuberculosis, and Oral Candidiasis). Five questions were designed for each module, which made 20 questions in total. The Google Forms quiz was designed to provide the students with the scores, correct answers, and the feedback directly after submission. The use of Google Forms for online formative assessment purposes is beneficial and practical, although the department only used it once throughout the practice sessions. For optimum benefit, the formative assessment should be completed multiple times throughout the course, so that the lecturers can obtain information about students' progress through several checkpoints.

\section{Background and Context}

Since the declaration by the World Health Organisation (WHO) of a global pandemic earlier this year, COVID-19 has been a public concern in many countries around the world (WHO, 2020). The pandemic caused schools, colleges, and universities across the globe to close campuses (Toquero, 2020). In response to this policy, many universities made an emergency, rather than planned transition, to online delivery of teaching and assessments (Lyons, Christopoulos, \& Brock, 2020). Fortunately, online learning and learning management systems are popular among students, allowing them to engage in learning activities (Karaksha et al., 2013).

Pharmacotherapy of Infectious Diseases, Immune System, and Cancer (FAF 323) was one of the courses at Andalas University's Faculty of Pharmacy that was impacted by this transition. This course consisted of two credits for the theoretical component and one credit for the practical component. The practical component was delivered for the first time this year due to the curriculum change.

Before the University closure, the assessment of this course consisted of pre-tests, individual assignments using case- based worksheets, and a group presentation. During the last four modules of this practice, the method of assessment was adjusted. The group assessment in these modules was eliminated in consideration for the high volume of internet usage required by students. Besides, the students' schedule had already filled by online synchronous lectures and other practice assignments. Thus, the assessment methods were changed to individual assignments and formative assessments to prepare them for the final exams. Both assignments and formative assessments were delivered online. This case study aims to explore the utilisation of Google Forms as a tool for online assessment for this course.

\section{Educational Description}

After the last module of FAF 323 practice sessions was completed, the Department of Pharmacology and Clinical Pharmacy administered an online quiz using Google Forms as the formative assessment for this practice. This platform was chosen because it is mobile phone friendly and easy to customise. The lecturers discussed the number of questions, the time limit, and the feedback for the students through a 
WhatsApp group. Based on the discussion, it was decided to administer 20 multiple choice questions on four modules that were delivered online. The modules were Systemic Lupus Erythematosus, Drug Hypersensitivity Reaction, Tuberculosis, and Oral Candidiasis. The number of questions was distributed equally between the number of topics, resulting in five questions for each module.

The questions were combinations of recall questions and analytical questions. The latter type of question was designed based on the cases previously delivered during the practice sessions. Following this proportion and considering the time limit, the authors developed four recall questions and one analytical question for each module. Thus, there are 16 knowledge questions and four analytical questions in total. The automatic grading feature of Google Forms was used, which consisted of points, correct answers and feedback. Each recall question weighed four points, while the analytical questions weighed nine points, resulting in 100 points in total.

To make the work more efficient, it was distributed equally between the lecturers who facilitated the practice sessions through a shared Google Forms page. Each lecturer created the questions based on the topic assigned, along with the points, correct answers and feedback, if applicable. The quiz was designed to provide the students with the scores, correct answers, and the feedback directly after submission. The scores were not included in the final grade components, confirming its formative nature.

The finished quiz was checked to ensure all the questions could be graded automatically and the points for each question has been input correctly. The finished quiz page was then cloned to make five identical pages to administer in each group of students. Each lecturer was assigned one group of students. The lecturer in charge was responsible for administering the quiz, ensuring all the students submitted their answers and gave feedback to the group of students based on their responses.

The quiz submission was not limited to one submission per email account in anticipation of the erroneous submission due to problems with internet connection. Although this option may provide opportunities for students to cheat, this was pre-empted by checking the responses. Every multiple submission with a significantly higher score in the later submission was considered as cheating; thus the lecturer could warn the respective student.

After the quiz session ended, the lecturers opened an online discussion session on WhatsApp groups, providing opportunities for further feedback by the students to ask questions and discuss topics that they had difficulties with. The lecturers could also provide feedback on the students' performance on the quiz, emphasising the topics or points that the students often missed.

\section{Outcomes and Recommendations}

From this study, the students' performances on the formative assessment were varied, the students of the fifth group had the highest average score compared to other groups (84.71, compared to 72, 71.63, 71.21, and 79.97). Regardless of the scores obtained by the students, the faculty also got an insight into the students' understanding, there were three frequently missed questions by the students of the first group and the second group, which was related to Systemic Lupus Erythematosus, Tuberculosis, and Drug Hypersensitivity Reaction topics.

Using Google Forms as the tool, the students could access the correct answers, feedback, and their score directly after they completed the quiz. The lecturers, moreover, could also get insight of students' performance. This platform provided a summary of students' scores, scores distribution, and percentage of students who gave the correct answer for each question. Another useful feature of this tool was the 'Frequently missed questions' insights. This feature helped the lecturers to check the question items for future improvement.

The use of Google Forms for online formative assessment purposes was beneficial and practical, although it was only used once throughout the practice sessions. For optimum benefit, the formative assessment should be conducted multiple times throughout the course, so that the lecturers can obtain information about students' progress through several checkpoints. The lecturers could also perform any necessary modification of teaching and learning strategies, allowing the students to gain benefits from the changes.

\section{References}

Karaksha, A., Grant, G., Anoopkumar-Dukie, S., Nirthanan, S.N., \& Davey, A.K. (2013). Student Engagement in Pharmacology Courses Using Online Learning Tools. American Journal of Pharmaceutical Education, 77(6), 125. https://doi.org/10.5688/ajpe776125

Lyons, K.M., Christopoulos, A., \& Brock, T.P. (2020). Sustainable Pharmacy Education in the Time of COVID-19. American Journal of Pharmaceutical Education, 84(6), 667-672. https://doi.org/10.5688/ ajpe8088

Toquero, C.M. (2020). Challenges and Opportunities for Higher Education amid the COVID-19 Pandemic: The Philippine Context. Pedagogical Research, 5(4), https://doi.org/10.29333/pr/7947

WHO [World Health Organisation]. (2020). Coronavirus disease (COVID-19) Pandemic. Available at: https://www.who.int/ emergencies/diseases/novel-coronavirus-2019 